\title{
Acting to the very limits of what you can do
}

$\mathrm{T}$ he preventive medicine prescription simply read: "Stop chasing stray cats." Dr. Paul Dhillon wrote it a few years ago for a 92-yearold patient who lived alone in a small Saskatchewan town. The woman had fallen on some steps, injuring a leg, as she chased stray cats from her yard.

As Dhillon applied a bandage to the patient's leg, she talked about coming to Canada as a war bride, raising a family and battling frigid Prairie winters. Dhillon suddenly felt privileged to be in a small town, where he could not only hear patients' stories but share their lives at the grocery store, hockey rink and emergency department. He thought that other rural doctors undoubtedly felt the same. And they too would have poignant tales to tell. The idea for a book was born.

Dhillon contacted physicians with rural practices, past or present, and asked them to submit recollections. Forty doctors from across Canada answered the call. The resulting book, The Surprising Lives of Small-Town Doctors, was published in time for this year's gathering of the Society of Rural Physicians of Canada, which was held in the Charlevoix region of Quebec. Dhillon's publisher, University of Regina Press, had to dissuade him from calling the book "Stop Chasing Stray Cats," although it was apt in more ways than one. Getting 40 busy doctors to put memories to paper and meet a deadline was, says Dhillon, "like herding stray cats."

Common themes emerged, including loneliness and Herculean challenges. Rural medicine is "acting at the very limits of what you can do and using everything you have in your head and in your hands to do the best for the patient," says Dhillon.

A typical story in the book was penned by Dr. AnneMarie Pegg. While visiting a remote nursing station in the Northwest Territories, a male patient arrived with dire heart problems. He needed immediate defibrillation. There wasn't a defibrillator available, so Pegg,

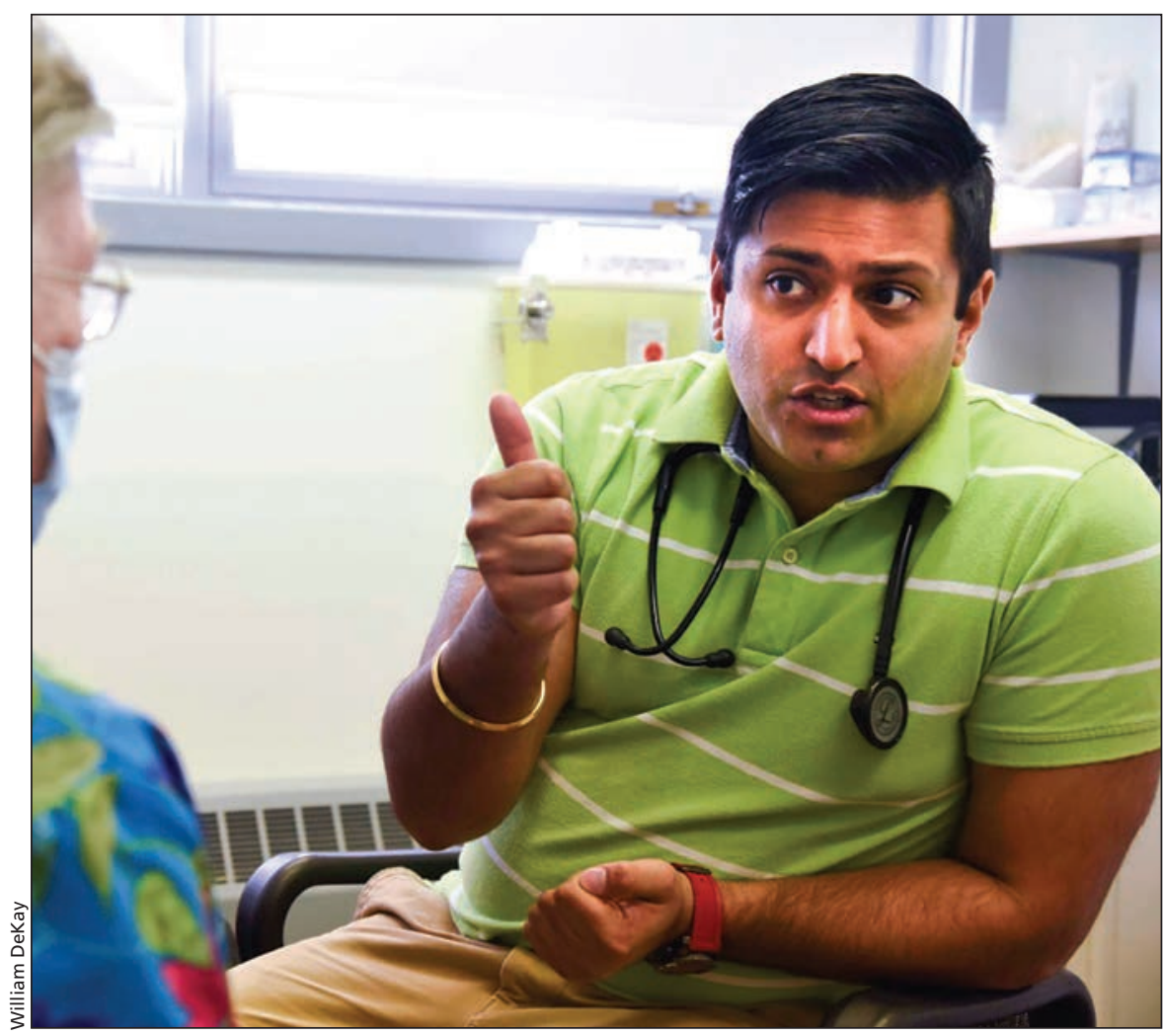

Dr. Paul Dhillon, while at work as a locum family physician in Leader, Saskatchewan.

with considerable trepidation, gave the man a precordial thump or, as the recovering patient said, she "punched me really hard in the chest." Pegg has developed a strategy for dealing with such very rural situations: "Put on your big girl panties and figure something out." The book reveals that most rural doctors have similar strategies.

This is not Dhillon's first book. While interning in Ireland, he found himself one day in Hartigan's Pub in Dublin with his best friend. "I think we had too many pints," he confesses. That led to a mutual challenge to write a book. The friend wrote a "beautiful" paragraph right in the pub and called it a day. Dhillon proceeded to write two books about interns' adventures in Ireland. He calls these fictionalized accounts of true events "faction." Both Time to Retract and Drogadishu surfaced on Amazon in 2011. Proceeds from sales went to charity, although Dhillon still had huge student debts to repay and largely limited his diet to potato chips. Dhillon says his career as a novelist is over, but his Regina publisher is pestering him to write another nonfiction book about his "pretty dangerous" six-week adventure last year in Africa fighting Ebola. ("Would I go and do it again? Yes, I would.”)

Dhillon was born in Victoria in 1981 to Indian immigrant parents. His father worked in various mining and forestry jobs; his mother became a teacher. Paul spent much of his childhood in the Tsawwassen suburb of Vancouver. Both Paul and his younger sister Jessy, who also became a doctor, were valedictorians at South Delta Secondary School.

After Paul graduated from medical school in 2009, specialized studies in such fields as disaster and tropical medicine took him to Scotland, England, the United States, Italy and Belgium. Finally, he did his family medicine residency at the University of 
Saskatchewan and, from 2012 to 2013 , he served as the president of the Professional Association of Internes and Residents of Saskatchewan, which helped earn him the Canadian Medical Association's Award for Young Leaders in 2013.

In 2012, the Dhillon siblings simultaneously won awards for essays in a New England Journal of Medicine contest. Paul's essay dealt, in part, with the need for doctors to touch their patients more, even if just to shake hands at the beginning of a consultation: "It shows you're human."

In 2013, he moved to Regina to serve as a locum doctor, filling shortterm vacancies in small towns. It was in such Saskatchewan communities as Leader, Porcupine Plain and Moosomin that Dhillon finally found his calling as a rural doctor, although that work has been frequently interrupted by working trips to Africa and serving several weeks a year as a captain in the reserves. He was interviewed for this article just a few days before joining a two-week military mission to the high Arctic. He expected to be patching up paratroopers who made poor landings on rocky terrain in $-60^{\circ} \mathrm{C}$ weather. After that trip, Dhillon was scheduled for a six-week stay in the Falkland Islands to replace an absent doctor.

By January 2017, Dhillon says, he will finally "settle down" as a family doctor in a small Saskatchewan town, but one big enough so Sarah Keegan, a midwife from Ireland who he married in June, can find a job. Despite settling down, he still plans to remain in the military reserves, travelling who knows where, and there will always be a buddy in Africa or the Falkland Islands looking for a temporary helping hand. Actually, settling down seems a term as incongruous for the globe-trotting Dhillon as it is for the stray cats that provoked his new book.

\section{Paul Gessell BA}

Art critic and journalist, Chelsea, Que.

CMAJ 2016. DOI:10.1503/cmaj.160304

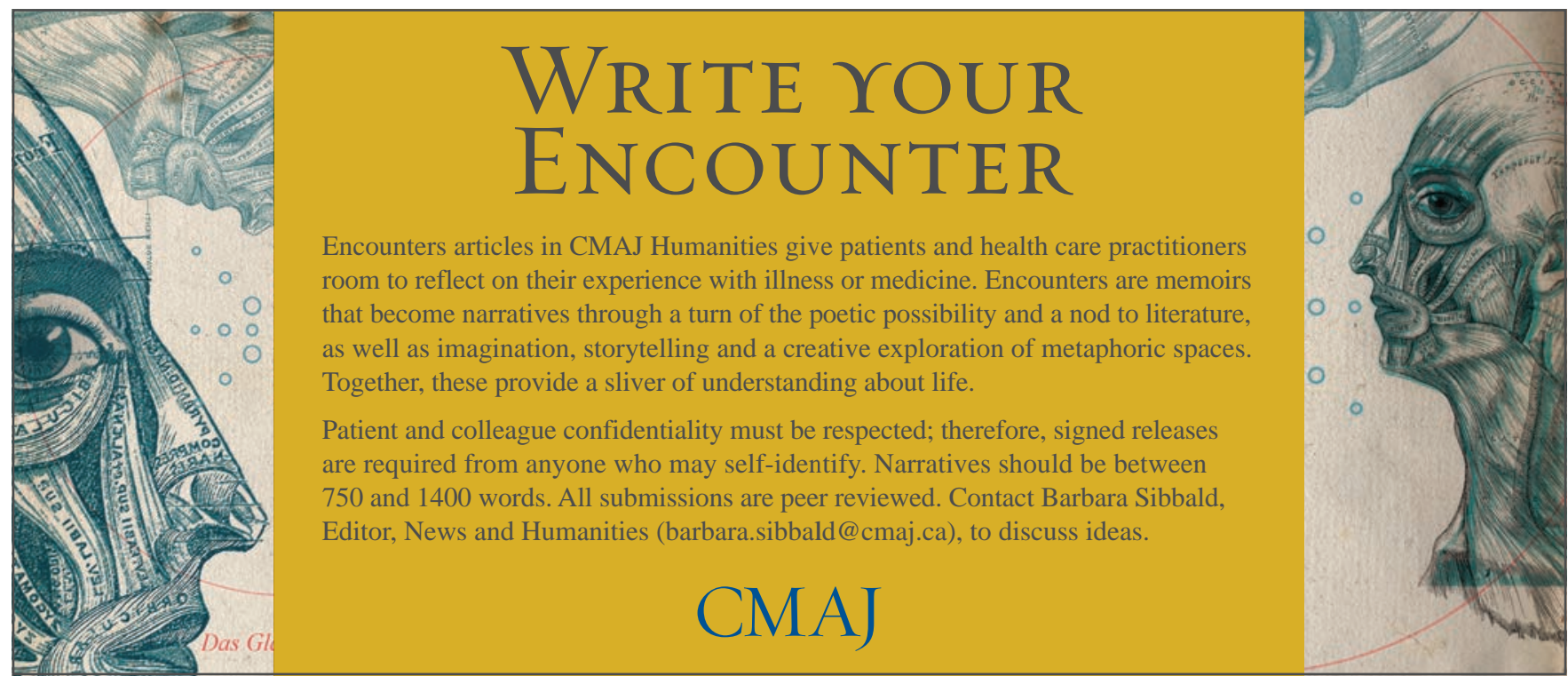

